It is worth observing that from this side of the island the four or five historic eruptions have occurred, and all the principal the rmo-mineral springs are confined mostly to this district.

It is at this very spot that the late earthquake has taken place, resulting in the total destruction of Casamicciola, with the exception of the hotels, baths, and a few well-constructed private houses. A hundred and twenty bodies have been excavated, and they are not all, besides 160 seriously wounded. At the village of Lacco thirteen houses have fallen, and five deaths are reported.

On March 4, at five and a half minutes past one p.m., a terrific shock shook the whole island, but its maximum intensity was at this point leaving Ischia and Forio almost uninjured, together with the villages on the opposite side of the mountain.

There was but a moment of premonitory trembling, when the terrific blow shook the houses about the ears of their inhabitants. The corpse of the shoemaker was found in his usual position, with the last between his knees, and we saw the corpse of a woman with the half-finished stocking in her hand and the needle in its sheath. The two cases show the suddenness of the catastrophe.

The first shock was described as a sudden blow beneath the feet, followed by a series of undulations, which appear from accounts to have radiated from a point which I shall immediately describe. This was followed shortly by faint vibrations, accompanied by loud subterranean thunder, such as was heard in the slight earthquake of last July.

On visiting the island a few hours after we were struck by the severity of the shock and by its extremely limited area. Fol lowing the methods adopted by our eminent countryman $\mathrm{Mr}$. Mallet, F.R.S., in his investigations of the great Neapolitan earthquake of 1857 , we have come to the conclusion that the undulations occurred in a series of closed curves radiating from a point which must have been situated about a quarter of a kilometre to the south-west of the upper town, that is in the direction of Lacco.

It is interesting to note that the seismographs at Naples and Vesuvius were not at all affected by the earthquake. This led Prof. Palmieri to conclude from the extremely local effects produced that the phenomenon was due to the excavation and removal of matter by the mineral springs and the collapse and falling in of the superincumbent ground. It seems difficult to satisfy oneself with the theory of my respected teacher and friend Prof. Palmieri for the following reasons :-

1. The collapse of earth in Cheshire in no way produces effect at all similar or equivalent to those under consideration, and yet the amount of salt in solution removed is equal to much more solid matter than is removed by the dilute mineral waters of Ischia which are also small in quantity. Landslips like that of Lyme Regis are quite incomparable in effects to the present case.

2. The waters that issued immediately after the disaster were as usual clear, and flowed at the same rate. If this explanation was tenable, then the collapse of the earth should have forced out a large body of water and vapour and have rendered the former turbid and muddy. Such however was not the case.

3. The disturbance in Ischia was coincident with the seismic movements that were felt in various parts of Europe from the 2nd to the 5th of March, and which was severe throughout Northern Italy.

We know from the following facts that Ischia cannot be reckoned amongst extinct volcanoes. The great number of fumaroles and thermo-springs that exist on its surface; the sand on the sea-shore in some parts is so hot a few inches from the surface that the hand cannot be borne in it; the continual seismic disturbances to which it was and is subject-all point to the conclusion that there still exists igneous matter not far from the surface.

The seismic waves of the beginning of March causing increased tension in the igneous matter through which they travelled would tend to rupture the superficial crust at its weakest pcint; the Island of Ischia presents to us such suitable conditions, and the volcanic matter, vapour, or lava may by those means have endeavoured to force its way towards the surface.

The formation of a fissure, together with the blow that would be produced by the immediate falling of such, would explain the phenomena. Much the same results occur from the formation of a dyke in an active volcanic mountain; in fact the conditions may be looked upon as analogous.
Although lava has failed to reach the surface on the present occasion, a repetition may be sufficient to produce an eruption such as has often occurred at this spot. We may look for the homologues of the present earthquake in that of A.D. 63 , pre ceding the outburst of Vesuvius in 79, or those that disturbed Pozzuoli and its neighbourhood immediately before the formation of Monte Nuovo, but which were not felt at Naples.

The fact that the undulations produced little effect on the southern side of the island shows the extreme thinness of the earth-crust at this spot; the weight and bulk of the superficial configuration acting as deterrent agents to the propagation of the seismic undulations to any great distance. The earthquakes in Ischia have at times been very disastrous, compelling various Greek colonies to forsake the island. There is generally a slight shock about once a year, nearly always accompanied by subterranean thunder. These have sometimes caused injuries, as on February 2,1828 , when three or four houses fell and some thirty people were killed. The details of the observa. tions being made will be published as soon as they can be formulated.

It is an interesting fact that since writing the above, on comparing notes with Signor P. Franco, my colleague, although our observations were quite independent and unknown to each other, yet we have arrived at exactly the same conclusion in almost every detail.

\section{H. J. JoHnSton-LAvis}

\section{UNIVERSITY AND EDUCATIONAL} INTELLIGENCE

OXFORD.-The following notice respecting scholarships in Natural Science has been published by Merton College :-

There will be an election in June next to one (or two) Physical Science Postmasterships.

The examination will begin on Tuesday, June 28 ; it will be held in common with Magdalen College, and at the same time and place. Candidates may give in their names at either College, but all will be regarded as standing at both, unless special notice is given to the contrary. In the event of election a candidate will be requested to state which College he would prefer. The Postmasterships are of the annual value of $80 l$., and are tenable for five years from election, provided that the holder does not accept or retain any appointment incompatible with the pursuance of the full course of University studies. After two years' residence the College may raise, by a sum not exceeding $20 \%$. per annum, the Postmastership of such Postmasters as shall be recommended by the Tutors for their character, industry, and ability. Candidates for the Postmasterships, if members of the University, must not have exceeded six terms of University standing, but there is no limit of age. The subjects of examination will be Chemistry and Physics. There will be a practical examination in Chemistry. Candidates will have an opportunity of giving evidence of a knowledge of Biology ; but it must be borne in mind that in such cases the examiners will look for evidence of an acquaintance with the principles of Chemistry and Physics at least equal in extent to that which is required in the Preliminary Honour Examination in the Physical Science School. A paper will be set in Algebra and Elementary Geometry (Books I.-VI.), and a Classical paper of the zstandard required by the University for Responsions.

Magdalen College has published the following notice respect. ing Natural Science Scholarships (Demyships) :-There will be an election at this College in June next to not less than seven Demyships, of which one at least will be Mathematical, one at least in Natural Science, and the rest Classical. No person will be eligible for the Demyships who will have attained the age of twenty years on October ro next. The stipend of the Demyships is $95 l$. per annum, inclusive of all allowances : and they are tenable for five years, provided that the holder does not accept or retain any appointment which in the judgment of the electors will interfere with the completion of his University studies.

THE Oldham Lyceum and Science and Art Schools, opened by Lord Derby last Thursday, seems to be a handsome and useful building, and under Mr. Phythian's superintendence we have no doubt much good work will be done in the future as in the past. Chemical and physical laboratories and other arrangements of scientific work have been provided for. 